\title{
ГЕОПРОСТРАНСТВЕННЫЕ ИНФОРМАЦИЯ, ДАННЫЕ, ЗНАНИЯ В ИСТОРИКО-КАРТОГРАФИЧЕСКИХ ИССЛЕДОВАНИЯХ
}

\author{
Роман Николаевич Баталов \\ Сибирский государственный университет геосистем и технологий, 630108, Россия, г. Ново- \\ сибирск, ул. Плахотного, 10, аспирант, тел. (952)911-67-60, e-mail: roman.batalov.95@mail.ru
}

\section{Людмила Константиновна Радченко}

Сибирский государственный университет геосистем и технологий, 630108, Россия, г. Новосибирск, ул. Плахотного, 10, кандидат технических наук, доцент кафедры картографии и геоинформатики, тел. (913)909-51-88, e-mail: 1.k.radchenko@sgugit.ru

В статье обозначается проблема различия понятий «геопространственная информация», «геопространственные данные» и «геопространственные знания». Путем анализа раскрываются отличительные особенности этих понятий. Предлагается определенное видение и толкование этих понятий применительно к историко-картографическим исследованиям. Затронут вопрос трансформации геопространственной информации из одного вида в другой на примере историко-картографических исследований, трансформации геопространственных данных в цифровой картографии, превращения геопространственной информации в знания с последующей трансформацией геопространственных знаний в электронно-вычислительной машине (ЭВМ). Приводятся примеры рассматриваемых понятий из исторической картографии.

Ключевые слова: историческая картография, геопространственная информация, геопространственные данные, геопространственные знания

\section{GEOSPATIAL INFORMATION, DATA, AND KNOWLEDGE IN HISTORICAL AND CARTOGRAPHIC RESEARCH}

\section{Roman N. Batalov}

Siberian State University of Geosystems and Technologies, 10, Plakhotnogo St., Novosibirsk, 630108, Russia, Ph. D. Student, phone: (952)911-67-60, e-mail: roman.batalov.95@mail.ru

\section{Lyudmila K. Radchenko}

Siberian State University of Geosystems and Technologies, 10, Plakhotnogo St., Novosibirsk, 630108, Russia, Ph. D., Associate Professor, Department of Cartography and Geoinformatics, phone: (913)909-51-88, e-mail: 1.k.radchenko@sgugit.ru

The article discribes the problem of the difference between the concepts of «geospatial information», "geospatial data» and "geospatial knowledge». The analysis reveals the distinctive features of these concepts. A certain vision and interpretation of these concepts in relation to historical and cartographic research is offered. The issue of transformation of geospatial information from one type into another is discussed on the example of historical and cartographic research, transformation of geospatial data into digital cartography, transformation of geospatial information into knowledge with subsequent transformation of geospatial knowledge in computer. Examples of the considered concepts from historical cartography are given.

Keywords: historical cartography, geospatial information, geospatial data, geospatial knowledge 


\section{Введение}

Понятия «геопространственная информация», «геопространственные данные» и «геопространственные знания» имеют много общего, но при этом они заметно различаются при конкретном применении в описании того или иного процесса. Возникает необходимость выявить смысловое содержание этих понятий и определить значение и применение геопространственных информации, данных и знаний в историко-картографических исследованиях, что и является целью данной статьи.

Для этой цели необходимо решить следующие задачи:

- рассмотреть классификацию геопространственной информации, раскрыть понятие «геопространственная информация», изучить и наглядно представить в виде схемы процесс трансформации геопространственной информации из одного вида в другой на примере историко-картографических исследований;

- раскрыть понятие «геопространственные данные», выявить его основные отличия от геопространственной информации, изучить и наглядно представить в виде схемы процесс трансформации геопространственных данных в цифровой картографии;

- раскрыть понятие «геопространственные знания», изучить и наглядно представить в виде схемы процесс превращения геопространственной информации в знания с последующей трансформацией геопространственных знаний в электронно-вычислительной машине (ЭВМ).

\section{Материалы и методы}

Основополагающим методом исследования выступает теоретический метод исследования, а именно описываются и анализируются несколько понятий: информация, данные, знания. Основываясь на методе классификации, а конкретно классификации геопространственной информации, приводятся примеры видов информации в историко-картографических исследованиях. Опираясь на исторический метод исследования приведены примеры геопространственных данных и знаний.

\section{Теоретическая часть исследования}

Геопространственная информация как динамическая характеристика разнообразия мира, может быть проявленной, непроявленной и отображенной.

Проявленная геопространственная информация присуща любым формам актуального бытия применительно к пространственно-временным ситуациям на местности. Она наблюдаема, измеряема и используется для поддержания функционирования систем. Подобно энергии она может быть законсервирована и переведена в статическое состояние, например, может храниться в форме документа, карты, электронного файла на компьютере и т. д. [3] На исторической карте, как и на любой другой карте, проявленная геопространственная инфор- 
мация записана на картографическом языке - языке различных по форме, размеру и цвету условных обозначений-символов [6].

Непроявленная геопространственная информация - это информация в потенциале, априори присущая пространству в его потенциальном бытии, но скрытая (в том числе и от сознания пользователя картографического произведения) до своей возможной востребованности. Непроявленная геопространственная информация может переходить в проявленную форму непосредственно и опосредованно. Непосредственный переход возможен в результате взаимодействия земных и воздушных систем вне участия социальных систем. Опосредованный переход информации происходит тогда, когда во взаимодействие с природными системами вступает социальная система [3].

Фиксируясь сознанием пользователя картографического произведения, непроявленная геопространственная информация трансформируется в отображенную, после чего получает возможность материализоваться, то есть перейти в материально закрепленную форму, например, в виде пространственной ситуации на исторической карте, с помощью творческих усилий историка или картографа.

Одна из форм существования геопространственной информации - непроявленная геопространственная информация, то есть геопространственная информация, существующая потенциально, независимо от осведомленности субъекта познания - пользователя картографического произведения. При оценке пространственно-временных свойств местности на картографическом произведении пользователь не может предполагать всех возможных вариантов развития ситуаций на местности - для него эта информация скрыта. С течением времени, по мере того, как он наблюдает динамику изменения ситуации, в его сознании постепенно отображается эта скрытая информация. Человеческое сознание может выделить только проявленную часть (актуальную). На примере исторической картографии проявленная геопространственная информация это первичная информация о местности в определенный период ее истории, представленная на историческом картографическом произведении. Составление исторической карты - это итог историко-географического исследования. Картографирование исторической информации помогает отразить распределение в пространстве отдельных избранных явлений и объектов, создавая таким образом основу для анализа и понимания исторической реальности с точки зрения временных эпох [4].

Человек интуитивно может выделить и непроявленную информацию, чего не способна сделать электронно-вычислительная машина. Искусственному интеллекту, в отличие от человека, на современном этапе развития ЭВМ под силу отражать только ту часть проявленной информации, для которой у нее имеются процедуры оценки внешнего мира, формализованные (запрограммированные) человеком. Самостоятельно вырабатывать процедуры познания современные машины не могут, то есть машина не способна самообучаться без участия человека. 
Отображенная геопространственная информация - это та часть проявленной информации, которая осмыслена (понята или востребована) пользователем картографического произведения. Непроявленная геопространственная информация - это информация о местности, скрытая до определенного времени. Отображаясь в сознании субъекта в процессе оценки обстановки, непроявленная геопространственная информация становится проявленной для других субъектов в результате нанесения изменений местности на историческую карту или передачи геопространственной информации другими средствами коммуникации, например, посредством языка. Этот пример отражает динамическую природу геопространственной информации.

Ряд ученых-картографов утверждает, что информация - это осмысленные данные. Например, Конон Н. И. в своей работе «Введение в проблематику информационного обеспечения геоинформационных систем» приводит определение информации как отражение в человеческом сознании данных об объектах материального мира и определенных формах их взаимосвязи [5]. Из этого утверждения следует, что все окружающее пространство - это данные, которые могут стать информацией, только если отразятся в человеческом сознании, то есть будут осмыслены. Таким образом, человеческий глаз, воспринимая карту местности через электромагнитные колебания видимой части спектра, наблюдает данные, и лишь обрабатывая их, получает из них информацию.

Основной отличительный признак данных - формализованное представление. Формализация подразумевает определенную структуру представления предмета познания. В эту структуру прописываются конкретные значения свойств предмета, его связи с другими предметами. Из этих элементов и формируется представление о предмете, его отличии от других.

Таким образом, то, что окружает человека, не может быть данными, потому что данные могут выделяться человеческим сознанием, а чтобы их выделить, необходимо знать, как их выделять, то есть данные не могут существовать без субъекта познания - человека (пользователя картографического произведения). В вычислительной технике обрабатываются, передаются и хранятся всегда только данные. Называя их информацией, подразумевают, что она формализована. Правила формализации определяют субъект познания - пользователь картографического произведения. Различные правила формализации геопространственной информации - это разнообразие абстрактных форм их представления. Картографическая информация, являющаяся частью геопростанственной информации, формализована на основе определенных правил [3]. Создание большинства карт, в том числе и исторических, основывается на системе базовых принципов, к которым относится принцип картографической формализации - использование системы условных знаков [1].

Отображенная информация - значит осмысленная. Осмысление при наличии определенных правил и соответствующего аппарата можно определить как формализацию. Происходит выделение существенных сторон предмета или яв- 
ления и формирование некоторых материальных конструкций, обладающих устойчивым характером, - данных [3].

На исторических картографических произведениях отображается только та информация, о которой у историка или картографа есть знания. И если говорить про местность или географическое пространство и их отображение в сознании пользователя исторического картографического произведения, то здесь будет уместен термин «геопространственные знания».

Геопространственные данные - это структурные части отображенной геопространственной информации. Исходя из этого, можно сделать вывод, что геопространственные знания, как понятие более высокого уровня, и есть отображенная геопространственная информация. Однако при таком определении геопространственных знаний существует некоторое противоречие. С одной стороны, для того, чтобы отобразить информацию, необходимы знания. Например, для того, чтобы содержание исторической карты отобразилось в сознании пользователя, пользователь должен обладать картографическими и географическими знаниями, и уметь ими пользоваться, то есть уметь читать карту [6]. К тому же знания являются продуктом осмысления и классификации, переработки и усвоения информации субъектом познания - пользователем картографического произведения [2]. С другой стороны, знания - это и есть отображенная информация. Дело в том, что при представлении геопространственных знаний в ЭВМ происходит их последовательная трансформация. Геопространственные знания фиксируются на материальных носителях. Далее осуществляется условное описание объектов местности, их атрибутов и связывающих их закономерностей. Затем осуществляется запись геопространственных знаний на языки представления. Это могут быть продукционные, семантические языки, фреймы. Результатом трансформации геопространственных знаний в ЭВМ является база геопространственных знаний на машинных носителях информации.

База геопространственных знаний - важный компонент экспертной системы (системы искусственного интеллекта). Содержание информации в такой базе характеризуется глубинной и явной структурой, включает максимально конкретное описание объектов с помощью числовых, строковых, логических или каких-либо других значений. Структура представляется в виде семантической сети, применение которой для получения искомой оценки предусматривает логические операции, позволяющие выделять свойства изучаемого объекта [7].

\section{Результаты и их обсуждение}

В результате проведенного анализа были сделаны следующие выводы. Геопространственная информация - это любые сведения (сигналы) об элементах местности (местных предметах), которыми обмениваются между собой живые и неживые системы и которые затем изображаются на картографических произведениях. Выделяют три вида геопространственной информации: 1) непроявленная - существующая потенциально, независимо от осведомленности субъекта позна- 
ния (пользователя картографического произведения); проявленная - нанесенная на картографическое произведение; 3) отображенная - отображенная в сознании пользователя картографического произведения. В процессе познания геодействительности субъектом познания происходит трансформация одного вида геопространственной информации в другой. Выделяют три вида этой трансформации: 1) из непроявленной информации в отображенную при помощи интуиции, предположения, прогноза; 2) из непроявленной информации в проявленную, а затем из проявленной - в отображенную путем познания; 3) из отображенной информации в сознании одного субъекта познания в проявленную путем фиксирования отображенной информации на материальном носителе, а затем из проявленной в отображенную в сознании другого субъекта познания.

Примерами непроявленной геопространственной информации в исторической картографии могут служить окружающие предметы (исторические здания, сооружения, памятники и т. д.), символьные изображения (буквенные (исторические тексты), числовые (даты), картографические (исторические карты, старинные географические карты, чертежи и т. д.), явления (войны, восстания, революции, миграции населения и т. д)). Проявленная информация может быть зафиксирована на исторических картах и других материальных носителях (исторических текстах, летописях и т. д.). Отображенная информация - отображенная в сознании субъекта познания информация о форме и границах государств или ареалов проживания народов, периоде времени, эпохе, назначении, материале постройки, этажности и других характеристиках исторических зданий, местах, районах сражений, восстаний, революций, направлениях миграций населения и т. д.

Геопространственные данные - это составные элементы проявленной или отображенной геопространственной информации, представленной в формализованном, то есть определенным образом структурированном, виде что обеспечивает возможность ее хранения, обработки и передачи. Основные отличия геопространственных данных от геопространственной информации - формализованное, то есть определенным образом структурированное представление предмета познания, и невозможность существования без субъекта познания - пользователя картографического произведения, определяющего правила формализации. Геопространственные данные после фиксации на материальных носителях в определенном в формате переходят (интерпретируются) в отображенную в ЭВМ информацию (на схеме эти данные представлены в базе данных электронной карты). Пользователь картографического произведения, наблюдающий электронную карту, выделяет геопространственные данные как части проявленной геопространственной информации и отображает их в своем сознании.

Примером геопространственных данных в исторической картографии может служить название исторического государства, а также соответствие этого абсолютного значения лингвистическому значению - например, Тюркский каганат. 
Геопространственные знания - это результат познания и осмысления субъектом познания (пользователем картографического произведения) геодействительности, верно отображенный в его сознании после осмысления и классификации, переработки и усвоения геопространственной информации. При представлении геопространственных знаний в ЭВМ происходит их последовательная трансформация, результатом которой является база геопространственных знаний на машинных носителях информации.

Примерами геопространственных знаний в исторической картографии могут служить знание маршрутов путешественников или полководцев, хода военных действий и т. д.

\section{Заключение}

В результате проведенных исследований выявлено смысловое содержание понятий «геопространственная информация», «геопространственные данные» и «геопространственные знания» и определено значение и применение геопространственных информации, данных и знаний в историко-картографических исследованиях. Рассмотрена классификация геопространственной информации, а также процесс трансформации геопространственной информации из одного вида в другой на примере историко-картографических исследований. Выявлены основные отличия геопространственных данных от информации и рассмотрен процесс трансформации геопространственных данных в цифровой картографии. Также рассмотрен процесс превращения геопространственной информации в знания с последующей трансформацией геопространственных знаний в электронно-вычислительной машине.

\section{БИБЛИОГРАФИЧЕСКИЙ СПИСОК}

1. Антонов, Е. С., Янкелевич С. С. Концепция нового вида карт, основанного на знаниях // Вестник СГУГиТ. - 2019. - Т. 24, № 4. - С. 188-196.

2. Варавва М. Ю. Информация, знания, научные знания как базовые категории новой экономики // Теоретическая экономика. - 2018. - №4. - С. 120-127.

3. Дулин, С. К., Духин С. В., Терляков О. А. О проблеме формирования геопространственных знаний в ГИС // Системы и средства информатики - М. : Федеральный исследовательский центр «Информатика и управление» Российской академии наук. - 2008. - Т. 18. № 1. - С. 186-208.

4. Калимуллина Г. С., Мингазетдинова Р. Ф., Нигматуллин А. Ф., Хизбуллина Р. 3. Роль картографирования информации в изучении истории родного края (на примере дворянских усадеб вокруг г. Уфы) // Вестник Башкирского университета. - 2019. - Т. 24, № 2. - С. 531-538.

5. Конон, Н. И. Введение в проблематику информационного обеспечения геоинформационных систем - М. : Недра, $2000-44$ с.

6. Лаврентьева, И. А. Карта - одно из основных средств формирования географических знаний // Ученые записки Казанского филиала «Российского государственного университета правосудия». - 2020. - Т. 16. - С. 413-416.

7. Maiellaro N., Varasano A. One-Page Multimedia Interactive Map // ISPRS Int. J. GeoInf. 2017. - Vol. 6 (2). - P. 34. 